\title{
The Influence of Fatigue Exposure Behavior of A6063- T6 Aluminum Fatigue Crack Growth Under Mixed Mode
}

\author{
Zulmiardi $^{1}$ Meriatna $^{2}$ and Meri Andriani ${ }^{3}$ \\ \{zulmiardi@unimal.ac.id\} \\ ${ }^{1}$ Department of Mechanical Engineering, Universitas Malikussaleh, Aceh Utara, Indonesia \\ ${ }^{2}$ Department of Chemical Engineering, Universitas Malikussaleh, Aceh Utara, Indonesia \\ ${ }^{3}$ Department of Industrial Engineering, Universitas Samudra, Langsa, Indonesia
}

\begin{abstract}
This research aims to know about the crack behavior on aluminum alloy A6063-T6 under mixed mode loading. The speciments made form Compact Tension Shear and by means of loading device, the angle between the load axis and the cracked surface was varied from agel $\alpha=900$ (mode I), $\alpha=600$ and $\alpha=450$ (mixe mode). Crack testing is performed by initial cracking followed by a constant fatigue load on a particular cycle through the survopulser device.The initial crack behavior and its propagation was monitored by digital microscope. Analysis of the test results gives the crack material toughness, cracking criterian, fracture toughness and fracture surface form A6063-T6 aluminum Alloy. The direction of crack propagation perpendicular to the angleof loading,in mode I the direction of crack propagates in the direction of pre crack fatty and forms ange 00from pre crack direction, in mode II andmixed mode with the height of the mode I component, the direction of each crack forms an angle of 260 and 420 from the pre crack direction and a fracture type friction occurs that precedes the open-type crack propagation in mode I. Observations by fractographic analysis use Scanning Electron Microscope shown the fracture surface is fatiguestriation).
\end{abstract}

Keywords: Aluminium A6061-T6, Mixed Mode, Fracture Toughness, Fatigue Crack Propagation.

\section{Introduction}

Parts or components of the machine [1] are often found to be failing due to the dynamic load of a voltage repeatedly. Repetitive or fluctuating stress, there will be voltage fluctuations within the components. When the fluctuations occur repeatedly as often as possible, there will be a fatic crack, although the maximum stress that occurs is still smaller than the static tensile strength of the material. Under these conditions, the mechanical properties of the material have changed [2]. Its ability to accept the maximum load will decrease as well and the analysis reveals that the maximum stress is actually still below the final strength of the material. Structural components ASM, Hand book [3] that often experience the conditions as mentioned above are: wall aircraft, ship, gear, shaft, fly wheel, clutch, and so forth.

Masanori Kikuci [4] conducted an experimental and simulated study of crack growth under mixed mode conditions with low cycle fatality in aluminum material A2017 which 
results showed that crack growth in low cycle fatigue was the appropriate plastic strain distance was the dominant parameter of crack growth fatigue and hoop stress dominate crack growth in mode I. Testing of dominant fatigue crack growth under condition mode II. It was also found that the direction of crack propagation can not be predicted by conventional methods. Observation of the fracture surface is also found a three-dimensional effect that affects the strength that is its nature.

Research on the expansion behavior of A2024-T351 aluminum crack in mixed mode loading has also been carried out by L W T Say [5] conducted a study on the fatigue crack growth treatment of IN 718 and laser-annealed alloy materials in hydrogen gas which results indicate that: the effect of hydrogen on increasing crack growth. Both laser-annealed and IN 718 assays have significant mixed mode differences in tensile strain and toughness but have a low fat content form in the air. For excess, the highest fatigue crack growth rate (Fatigue Crack Growth Rate) occurs.

W.E.Krupp, D.W. Hoppner, [6] conducted a study of crack propagation in aluminum alloys in corrosive environments on aluminum material A2024-T3; A7075-T6 and 7075-T76 results show that For all of the aluminum mixtures investigated, an increasingly rapid cracking caused by corrosive environments occurs only in the early stages of fracture development. The next stage at high levels, crack speed in the air dry, moist air and in brine tend to be the same. Front-fracture rotation of crack stretching into shear fractures usually occurs after a decrease in corrosive environmental effects at the rate of growth of cracks in thin sheet material G.E. Dieter [7]. Decreased corrosive environmental effects on crack speed are common in thick sections without measurable crack rotation. The aluminum alloy 7075 is much more sensitive to changes in the corrosive and frequency environment than the 2024 aluminum alloy so that the three materials are suitable for aircraft use. Aoki, S., Kishimoto, K., Yoshida, T., Sakata, M., and Richard [8] describes the elastic with the height of the mode II component, the initial crack at frictional fracture occurs near the surface of the fracture at the end of the specimen, and the other crack occurs dimple at its thickness.

Husaini, and Kishimoto [9] describes the fracture behavior in blend mode in PC/ABS Blends under mixed mode loading with CTS specimens in which the price ratio in blend mode with the height of the mode II component, the initial crack at the friction type initially occurs at the crack tip, then the other crack occurs on the open type on its surface as well as on the cracking process of shear type, and spreads until the final failure occurs. Research on the behaviore of expansion of aluminum crack A2024-T351 in mixed mode loading by Husaini, and Kishimoto [10] has also been done, where with small holes in front of the crack tip affect the direction of crack propagation.

\section{Literature Review}

\subsection{Material Cracking}

Some types of cracks or Failure materials are; brittle fracture,ductile fracture, and due to fatigue factor crack [11]-[12]. With the presence of a crack mechanical science as applied science has shown that, material toughness, crack size and stress levels are interrelated in order to estimate the susceptibility of various failure structures Calister, Wiliam D, [13]. The above relationship can be shown as figure.1. 


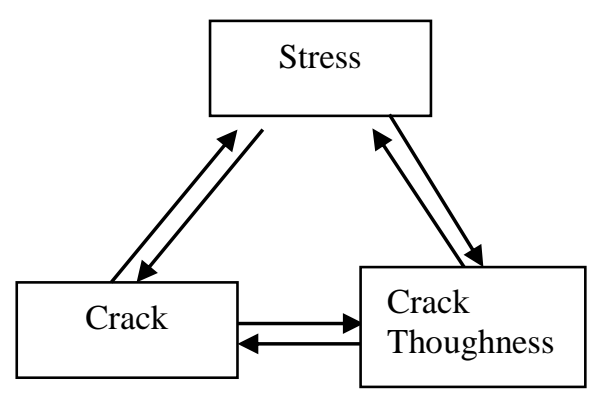

Figure 1: Crack Control Factor

With the calculation its micromecanic in crackcing process toplane, cracking criterian Jastisin limits. KI and KII its material propeties. Stress Intensity Factor according to Murakami (1987) to CTS spesimen trate the present with equotion :

$$
\begin{aligned}
& K_{I}=F_{I} \frac{P_{i n}}{W t} \sqrt{\pi a} \\
& K_{I I}=F_{I I} \frac{P_{i n}}{W t} \sqrt{\pi a}
\end{aligned}
$$

Where:

$\mathrm{W}=$ width of the speciment

$\mathrm{t}=$ thick speciment

$\mathrm{a}=$ initial crack length

I and II its for mode I and mode II

$\mathrm{F}=$ correctionfactor $: 2.85$

Equation (1) and (2) can be used to obtain the fracture toughness value which is a test to measure the resistance of a material to the expansion of the crack. The various loading positions for mode I, mode II and mixed mode can be shown in Figure 3.

(Micheal Ashby, 1987) at steady state condition, fatigue crack growth ratethe present with:

$$
\frac{\mathrm{da}}{\mathrm{dN}}=\mathrm{A} \Delta \mathrm{K}^{\mathrm{m}}
$$

$$
\Delta K=\Delta \sigma \sqrt{\pi a}
$$

$\Delta K=K_{\max }-K_{\min }$

$$
K_{\text {max }}=\sigma_{\text {max }} \sqrt{\pi a} K_{\text {min }}=\sigma_{\text {min }} \sqrt{\pi a}
$$

For CTS spesiment steady state condition, (Agus Suhartono, n.d.) fatigue crack growth rate the present with:

$\left(\frac{d a}{d N}\right)$ 


$$
\frac{d a}{d N}=\frac{\Delta a}{\Delta N}
$$

Stress intensity $(\Delta K)$ :

$\Delta K=K_{\max }-K_{\min }$

Murakami (1987)

Stress intensity maximum:

$$
K_{\text {max }}=F \frac{P_{\text {max }}}{W t} \sqrt{\pi a}
$$

Stress Intensity Minimum:

$$
K_{\min }=F \frac{P_{\min }}{W t} \sqrt{\pi a}
$$

stress ratio):

$$
R=\frac{P_{\max }}{P_{\min }}
$$

\section{Method and Materials}

This research consists of several stages of work as follows:

a) Procurement of necessary materials and equipment, including the tests for tensile test and crack test

b) Make fatigue pre crack to every CTS speciment bevore fatigue test.

c) Setup of fatigue test equipment on servopulser as shown in Figure 1.

d) Preparation of data retrieval.

e) Testing of Static tensile test using ASTM E8 standard to result of real properties of A6063-T6 material.

f) Testing of intensity factor critical stress ststic test to result of critical stress Intensity Factor value of aluminium A6063T-6 using JSME standard CTS speciment to result of critical intensity factor value of aluminium A6063-T6 material.

g) Adjust the angle by using loading deviceas pigure 3 which angles between the load axisand the cracked surface are varied from $\alpha=90^{\circ}$ (mode I), $\alpha=60^{\circ}$ and $\alpha=45^{\circ}$ (mixed mode).

h) Testing of fatigue crack growth Davis HE, [14].

i) Data analysis of test. 


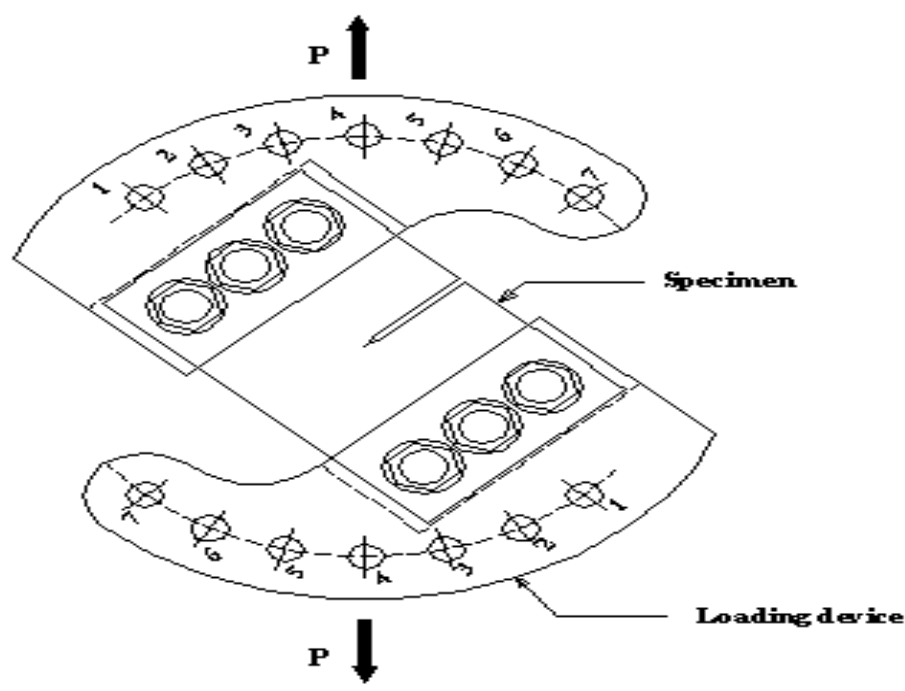

Figure 3. Loading deviceH.A. Richard Benith (1983)

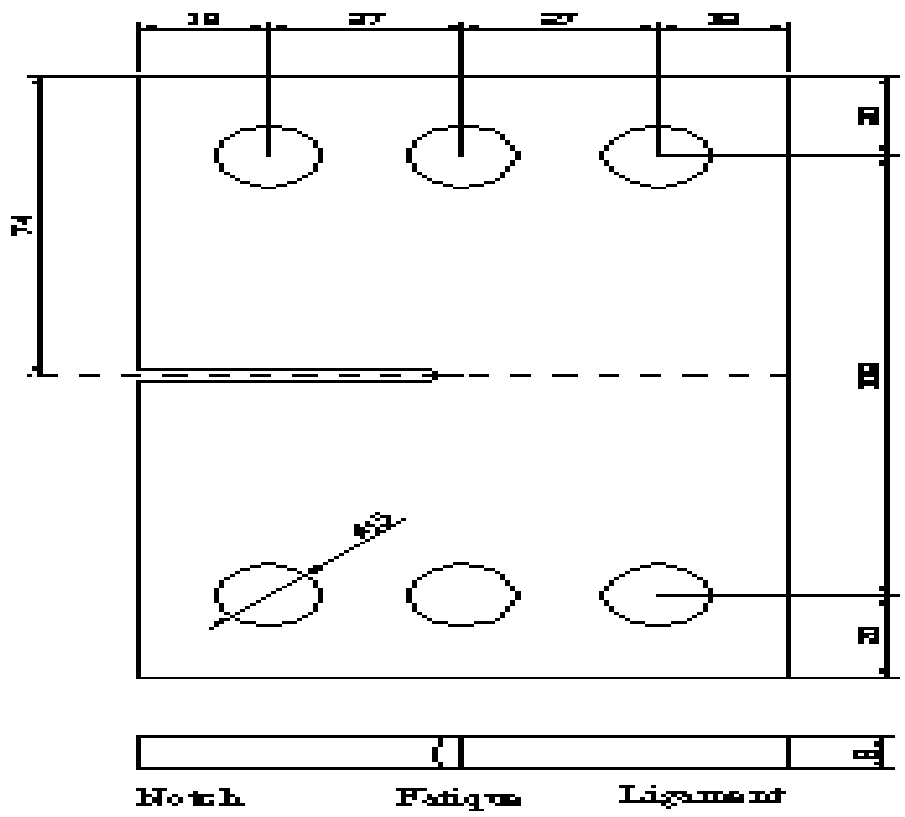

Figure 4. CTS Spesiment (“JSME Standard”, n.d.) 


\section{Results and Discussion}

\subsection{Result of Tensile Static Test}

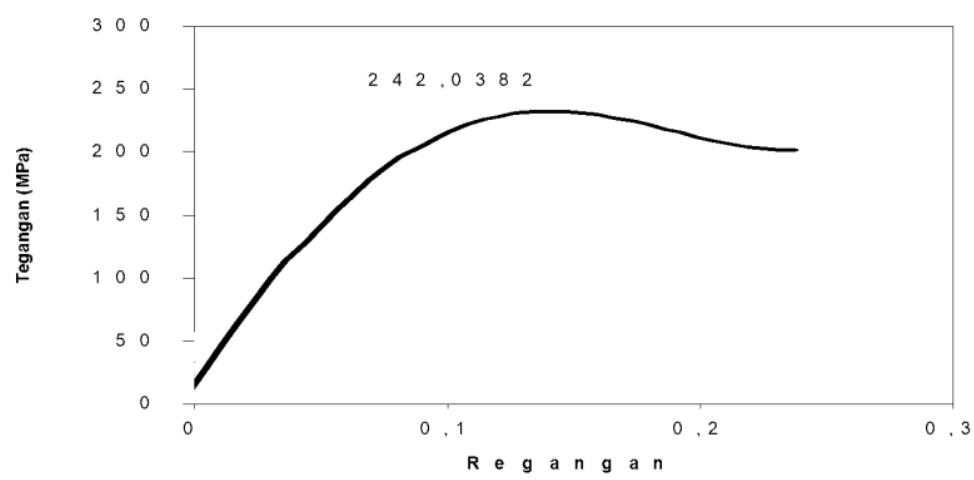

Figure 5. Graph of Stress Relation Vs Strain Speciment Tensile Test (Benner [15])
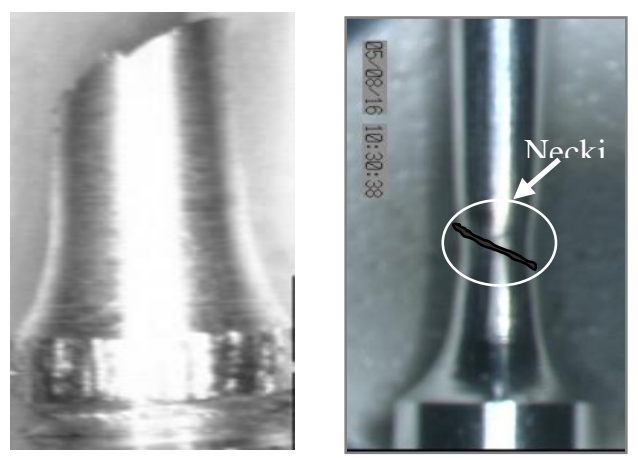

Figure 6. ASTM E8 (Roberta A. Storer, [16] Spesiment Standard After Failure Table 1. Mechanical Properties of Aluminum A 6063-T6Result of Tensile Stess Test

\begin{tabular}{|c|c|}
\hline Ultimate tensile stength & $242.04 \mathrm{MPa}$ \\
\hline $0.2 \%$ Yield strength & $172 \mathrm{Mpa}$ \\
\hline $0.2 \%$ Yield strength & $172 \mathrm{Mpa}$ \\
\hline Modulus of elasticity & $68.3 \mathrm{Gpa}$ \\
\hline Shear strength & $154 \mathrm{Mpa}$ \\
\hline Poison ratio & 0.33 \\
\hline Elongation & $16.4 \%$ \\
\hline
\end{tabular}

Akhmad HW, (2009), the final failure of the specimen occurs due to the shear fracture with the surface failure uprooted to an angle of $45^{\circ}$ as shown in Figure 6. This shows the ductile fracture of the A6061-T6 aluminum material. Mechanical properties of A6063-T6 material result of tensle testing as shown in table 1 and, graph of stress relation vs strain speciment tensile test (Fig. 5) Saito., [17]. 


\subsection{Result of Critical Intensity Factor Static Test}

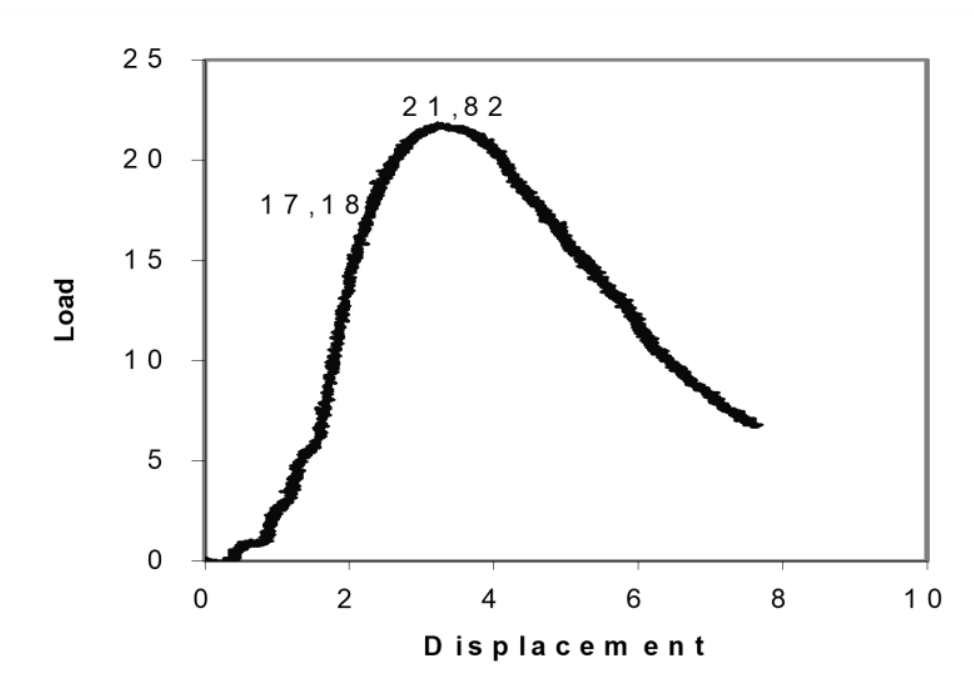

Figure 7. Graph of Static Test Result of Critical Intensity Factor at $\alpha=90^{\circ}$ (Mode I)

Figure 7 shown is the result of stess intensity factor (KI) used static quation at $\alpha=900$ (mode I)as shown at figure 7and record as KIin, it is fracture toughness value of Aluminium A6063T6, at cack initiation Pin $=17.2 \mathrm{KN}$, stess intensity factorvalue is : KIin $=25,15 M P a \sqrt{m}$.

The final failure of the specimen occurs due to the shear break fracture with the surfacefracture uprooted to an angle of 450 as shown in Figure 6. This shows the ductile fracture of the A6061-T6 aluminum material.

\subsection{Result of Fatigue Crack Gtrowth under Mixed Mode}

Prior to the implementation of fatigue test in advance some of the sentiments were given axial fatigue load using Servopulser tool. This loading is carried out at a Pressure amplitudes of $380 \mathrm{MPa}$ and loaded up to 107 cycles. This condition refers to the results of fatigue test against aluminum A 6063-T6 which has been reported through the previous paper. The form of crack propagation recorded on the microskop digital monitor screen. The result of fatigue crack growth under mixed modepresent as graph of the linkage rate of Propagation fracture fatigue vs range of stress Intensity for all three conditions loading: $\alpha=900$; mode I); $\alpha=600$ and $\alpha=450$ (Mixed mode) shown in Figure 11.

From the graph in Figure 7 it can be seen that for the angle of loading 900 the relationship da/dN and $\mathrm{K}$ is more linear and the smaller the loading angle at the end of the graph step of the forming the more upright. At the loading angle of 450 can be shown the increasing rate of crack growth $(\Delta \mathrm{K})$. For all three modes can be seen at Figure $8,9 \& 10$. 


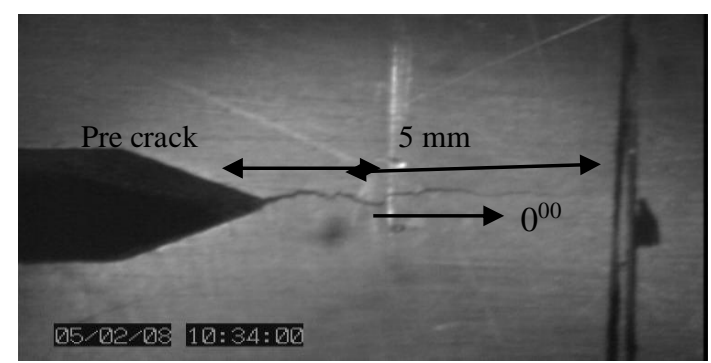

Figure 8. The direction of crack propagation Fatik $\alpha=90^{\circ}$

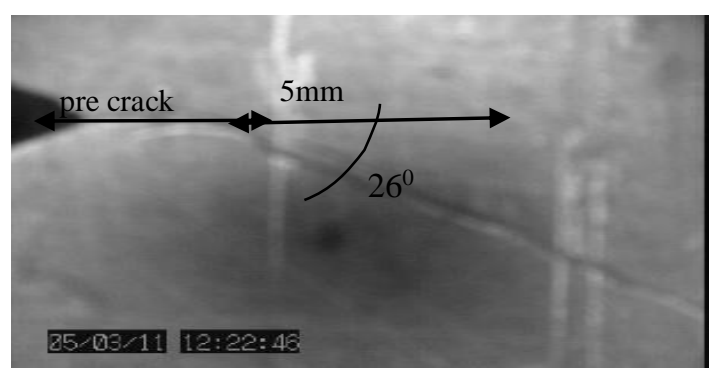

Figure 9. The direction of crack Propagation Fatik $\alpha=60^{\circ}$

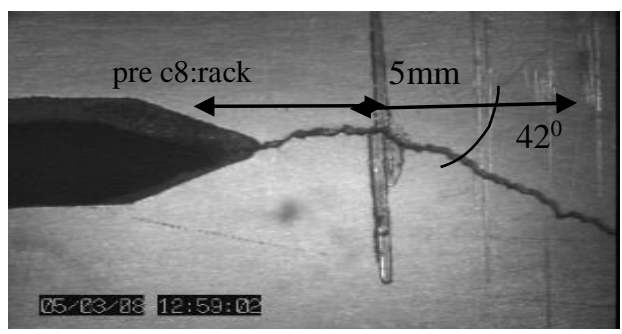

Figure 10. The direction of crack propagation Fatik $\alpha=45^{0}$

From the picture 7,8 and 9 shown where the loading mode $\mathrm{I}=900$ occurs in the direction of crack propagation the makeangle 00 , in the loading of mixed mode $=600$ occurs the direction of growth of fatigue crack the make angle 260 and on mixed mode loading $=450$ occurs the direction of growth of fatigue crack the make angle 420. This implies that the smaller the angle of loading, the direction of growth of fatigue crack (angle (0) is greater as last in the loading of mixed mode $(\alpha=450)$ obtained by the direction of growth of fatigue crackthe make angle Figure 10 shows the relationship between the angle of loading angle and the direction of growth of fatigue crack (00) for various loading conditions. The crack growth of the digital and digital microscope recording shows that the crack propagation is not completely straight but twisted and serrated, it is influenced by fatigue loading and also shows the properties of aluminium material itself which is ductile. The graph of the linkage rate of propagation fracture fatigue vs Range of stress Intensity for all three conditions loading: $\alpha=$ 900 (mode I) 0, $\alpha=600$ and $\alpha=450$ (Mixed mode) shown in Figure 6. From Figure 10, graph of the relationship spreading rate of fatty crack Vs Intensity range stress for the incorporation 
of the three loading conditions ( $\alpha=900$ modes I), $\alpha=600$ and $\alpha=450 . \mathrm{K}$ is more linear and smaller, the loading angle at the end of the graph step of the formation is getting more upright.

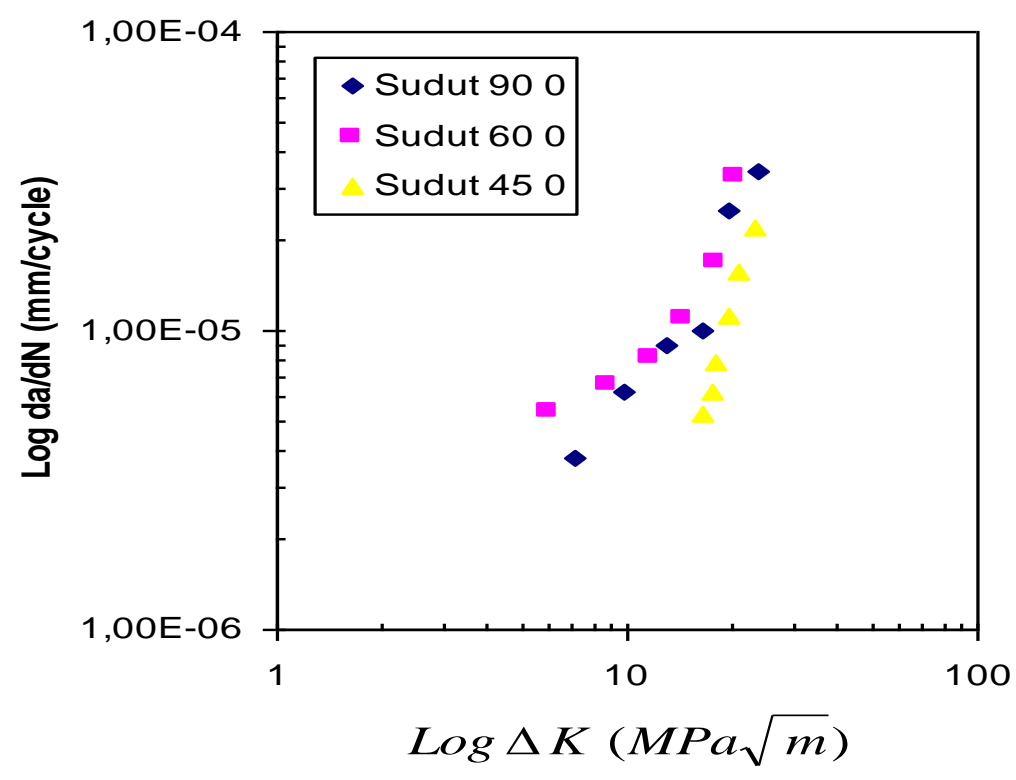

Figure 11. Graph of the Linkage Rate of of the Linkage Rate of Propagation Fatigue Fracture Vs Range of stess Intensity for all Three Conditions Loading: 900 modes I), $\alpha-450$ Propagation Fracture Fatigue Vs Range of Voltage Intensity for all three conditions Loading: $\alpha=900$ mode I), $\alpha=600$ and $\alpha=450$ (Mixed mode). At the loading angle of $\alpha 450$ can be shown the increasing rate of crack growth $\alpha=450$ (Mixed mode) shows that for the angle of loading 900 the relationship da $/ \mathrm{dN}$ and $\Delta \mathrm{K}$ more linier and more small the loading angel at final testing step, the result of more vertical. At The loading angel 450 shown be fatigue crack growth rate increase.

\subsection{Result of Scanning Electron Microscope (SEM) Test}

Surface Fracturea longfatigue crack growth which after devidet hattakea replica and it coat whith carbon and cromium, after that fractografy test using SEM with 700x enlargemenfor shown topology mikro surface fracture Marrow J, (2009). Take one foto fromper specimen atfracture zone mode I ( $\alpha=900)$, modeII $\alpha=600,(\alpha=600)$ and mixe mode ( $\alpha=450$ ). It photopresent inpicture 12, 13 and 14 . 


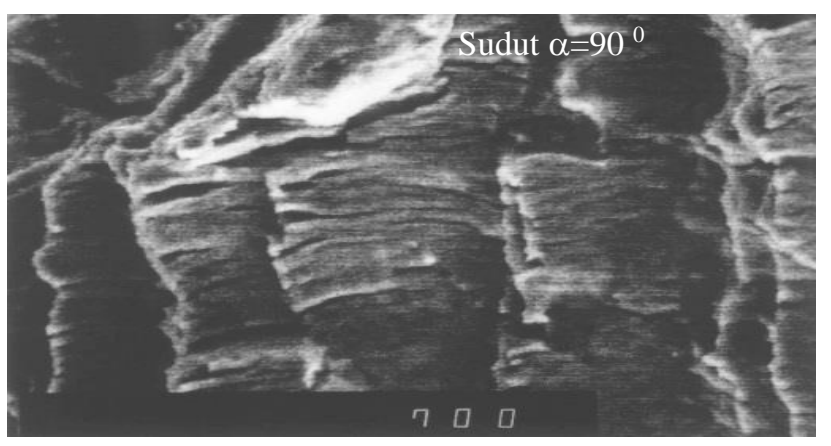

Figure 12. Fractographic Alloy Frame of Aluminium A6063-T6 Fractografy Test Using SEM with 700x Enlargement mode I $\left(\alpha=90^{\circ}\right)$

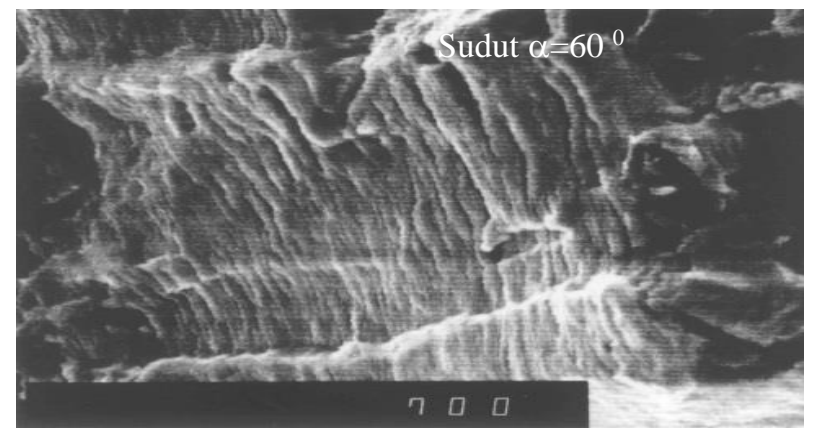

Figure 13. Fractographic Alloy Frame of Auminium A6063-T6 Fractografy Test Using Scanning SEM with 700x Enlargement for mode Campuan $\left(\alpha=60^{\circ}\right)$

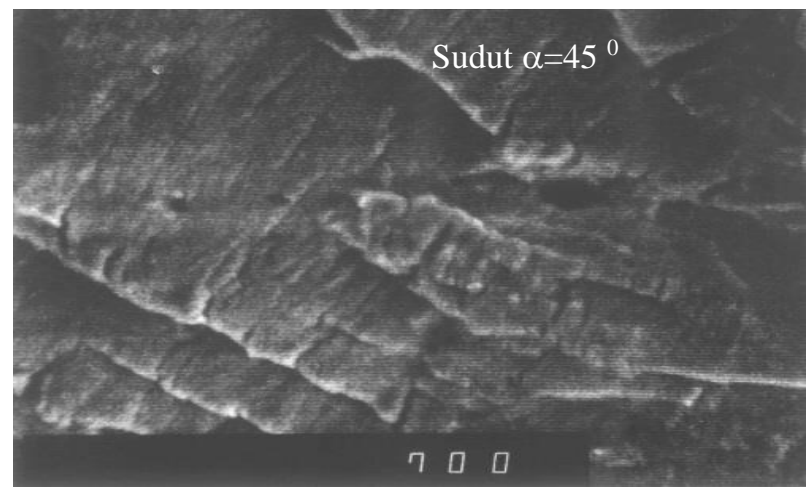

Figure 14. Graph of the Linkage Rate of Propagation Fatigue Fracture Vs Range of stess Intensity for all Three Conditions Loading: $90^{\circ}$ modes I), $\alpha-45^{\circ}$

In an attempt to identify the specimen fracture form, a SEM test was performed. The result of fracture surface analysis of the specimen in the fracture area in the mode I $(\alpha=900)$, mixed mode $\alpha=600)$ and mode $(=450)$ with $700 \times \mathrm{x}$ largement is shown in figure 12,13 , and 14 . 
From the fraktografy result tes of three fracture crackand three loading engle seen be striation fatigue. Which the result of cyclus stress which direction the influence by direction loading angel. Its striationgive information thatis fracture failure fracture this material aluminium A6063 T6, its production fatigue failure and its material is ductile Davis HE, [22].

\section{Conclusion}

From the results and discussion above can be drawn some conclusions as follows:

1. Price of critical stressintensity factor Aluminum A6063-T6: KIin $=25,15 \mathrm{MPa} \sqrt{\mathrm{m}}$.

2. By dominating the mode I component, the direction of the crack propagation is erect in the direction of loading, then the increase of the mode II component becomes predominantly friction type friction, the initial fracture occurs in friction type fracture, then the fracture criterion does not follow the maximum stess criterion.

3. Cracks propagate normally perpendicular to the angle of loading. The smaller the loading angle, the smaller the crack propagation angle. In the mode I $\left(\alpha=90^{\circ}\right)$ the direction of the crack propagates in the direction of the crack crack at an angle $0^{0}$ from the pre crack fatigue direction, in the blend mode, $\left(\alpha=60^{\circ}\right)$ the direction of crack propagates to an angle of angel $=26^{0}$ from the pre crack fatigue direction, $\alpha=$ $45^{\circ}$ ) the direction of cracking creates an angle $42^{0}$ from the pre-crack fatigue direction.

4. Loading stress and stree affects fatigue crack propagation, where the greater the load the material receives the smaller the cyclusts occur and the faster the crack growth rate vice versa.

5. From the fractography analysis result with SEM three angle of loading shows that the fracture is fatigue striation and the smaller the grain loading angle is caused by fracture type striation.

\section{References}

[1] E. F. Faupel, H Joseph, Fisher, Engineering Design, 2nd ed. New York: John Willey and Sons, 1981.

[2] Timings RL, Engineering Materials, Addison. Wesley Longman Limited.

[3] ASM, Hand book, ASM, Hand book, (Ferrous, Non Ferrous and Aluminium Alloy) Vol. 2. American Society for Metal, 1975.

[4] Masanori Kikuci, "Studi on The crack Grouth Path under Mixed mode Condition For low Cycle fatigue problem," SMIRI, vol. 1, 2001.

[5] H. H. L. A. R. K. and S. L.W.T say, "Fatigue Crack Growth Behavior of Laser Anneal IN 718 Alloy in hydrogen," Corros. Sci. 46, 2004.

[6] and E. K. W. W.E.Krupp, D.W. Hoppner, "W.E.Krupp, D.W. Hoppner, and E.K. Walker, Crack Propagation of Aluminium Alloys in Corrosive Environments, Lockheed- California \& Co. Burbank, California.," Canyon Res. Lab.

[7] G.E.Dieter, Mechanical Metalurgi,. New York: Mc Graw Hil Book Company.

[8] H. . Aoki, S., Kishimoto, K., Yoshida, T., Sakata, M., and Richard, "Elastic- PlasticFracture Behavior of an Aluminium Alloy under Mixed Mode Loading," J.Mechanical Phys. Solid, vol. Vol.38, N0, pp. 195-213, 1990. 
[9] K. Husaini, and Kishimoto, "Fracture behavior in blend mode in PC /ABS Blends under mixed mode loading," Proc. 2nd Int. Conf. Exp. Mech. ICEM, Singapore, pp. 111-116, 2000.

[10] K. Husaini, and Kishimoto, "Mixed Mode Crack Extension Behavior of A 2024-T351 Aluminium,”, Proc. Int. Semin. Exp. Mech. (ETM 2002), pp. 69-77, 2002.

[11] Calister, Wiliam D, Materials science and engineering 7 th. Canada: John Wiley \& Sons, Inc., 2007.

[12] Y. Murakami, Stress Intensity Factor Handbook, vol. 2. Pergamon Press, 1987.

[13] Micheal Ashby, Engineering materials,. Pergamon Press Oxford, 1987.

[14] Agus Suhartono, Life Time Prediction Ditinjau dari Fatik dan Mekanika Patah,. Jakarta, 12440: Yayasan Puncaksari, Jakarta, 12440.

[15] F. G. Davis HE, The Testing of Engineering Materials, Fourth Edi. New York: Mc Graw-Hill Book Company, New York, 1982.

[16] K. B. H.A. Richard, "A Loading device for the creation 0f Mixed Mode in Fracture Mechanics," Int. Fract. Mech., pp. 55 - 58, 1983.

[17] "JSME Standard."

[18] B. J. M. Benner, Ilmu pengetahuan bahan Aksara. Jakarta: Bhatara Karya Jakarta, 1985.

[19] Roberta A. Storer, Annual Book of ASTM Standard 1996, Volume 03. Easton, MD, USA.: Easton, MD, USA., 1996.

[20] Akhmad HW, Buku Panduan Praktikum Karakterisasi Material 1. Jakarta: Fakultas Teknik UI, Jakarta, 2009.

[21] sudira T. dan S. Saito., Pengetahuan Bahan Teknik Jakarta: Pradnya Paramita, Ke lima. Jakarta: Pradnya Paramita, 2000.

[22] Marrow J, “Materials Science Internet Microscope,” UMIST Univ. Manchester, 2009. 